\title{
The Validity and Reliability Study of Turkish Version of the Growth Motivation Index (GMI)
}

\author{
Ümran AKIN ${ }^{1}$, Ahmet AKIN $^{2}$ and Sümeyye ÖZKAYA ${ }^{1}$ \\ ${ }^{1,2,3}$ Sakarya University Faculty of Education Department of Educational Sciences
}

\begin{abstract}
The present study investigated the validity and reliability of Turkish version of Growth Motivation Index (Bauer, Park, Montoya, \& Wayment, 2015). The sample of study consists of 248 university students. Of the participants 171 were female and 77 were male and the mean age of them was 20,3. In this study construct validity and internal consistency reliability coefficients of the scale were examined. The results of confirmatory factor analysis indicated that the two-dimensional (GMI-Reflective and GMI-Experiential) model was well fit $\left(x^{2}=35.76, d f=18, R M S E A=.063, N F I=.96, C F I=.98, I F I=.98\right.$, and SRMR=.031). Cronbach alpha internal consistency reliability coefficients of the were found as .81 for reflective subscale and .87 for experiential subscale. Overall findings demonstrated that this scale had acceptable and fairly high validity and reliability scores.
\end{abstract}

Keywords: Growth Motivation, Confirmatory Factor Analysis, Validity, Reliability

\section{Introduction}

Growth motivation has generally ben defined as a desire toward progress, exploration, seeking challenges, learning, and the increasing actualization of one's potentials (Maslow, 1968). It includes two basic facets of growth motivation (reflective and experiential) that steer personality development toward two paths of eudaimonic personality development (Bauer, Park, Montoya, \& Wayment, 2015). There is a strong need to have a reliable and valid measurement tool to measure Turkish individual's levels of growth motivation. Thus the aim of this research is to translate the Growth Motivation Index (Bauer et al., 2015) to Turkish and to examine its psychometric properties. This questionnaire contains 8 items (e.g., "I ask myself "what if..." questions that place me in others' shoes, such as "What would I think or feel in this situation if I were of a different race or ethnicity?',.') with each item rated on a 7-point Likert-type scale. The CFA provided a favorable fit to the data $\left(\mathrm{x}^{2}\right.$ with $\left.19 \mathrm{df}=25.939, \mathrm{p}=.131, \mathrm{x}^{2} / \mathrm{df}=1.37, \mathrm{CFI}=.98, \mathrm{NNFI}=.97, \mathrm{RMSEA}=.035\right)$. GMI-Reflective and GMI-Experiential showed reasonable internal consistency, with Cronbach's alphas of .72 and .74, respectively. The two factors were also significantly correlated, $r=.60$.

\section{Method}

The study was conducted on 248 university students from different programs of Education Faculty of Amasya University, Turkey. Of the participants 171 were female and 77 were male and the mean age of them was 20,3. Primarily the Growth Motivation Index was translated into Turkish by three academicians. After that the Turkish form was back-translated into English and examined the consistency between the Turkish and English forms. Than Turkish form has been reviewed by two academicians from educational sciences department. Finally they discussed the Turkish form and along with some corrections this scale was prepared for validity and reliability analyses. In this study confirmatory factor analysis (CFA) was executed to confirm the original scale's structure in Turkish culture. As reliability analysis internal consistency coefficient and the itemtotal correlations were examined.

\section{Results}

Validity. The results of confirmatory factor analysis indicated that the two-dimensional (GMI-Reflective and GMI-Experiential) model was well fit $\left(\mathrm{x}^{2}=35.76, \mathrm{df}=18, \mathrm{RMSEA}=.063, \mathrm{NFI}=.96, \mathrm{CFI}=.98\right.$, IFI=.98, and SRMR=.031). According to these values it can be said that the structural model of Growth Motivation Index which consists of two factors was well fit to the Turkish culture (Marsh, Balla, \& McDonald, 1988). 


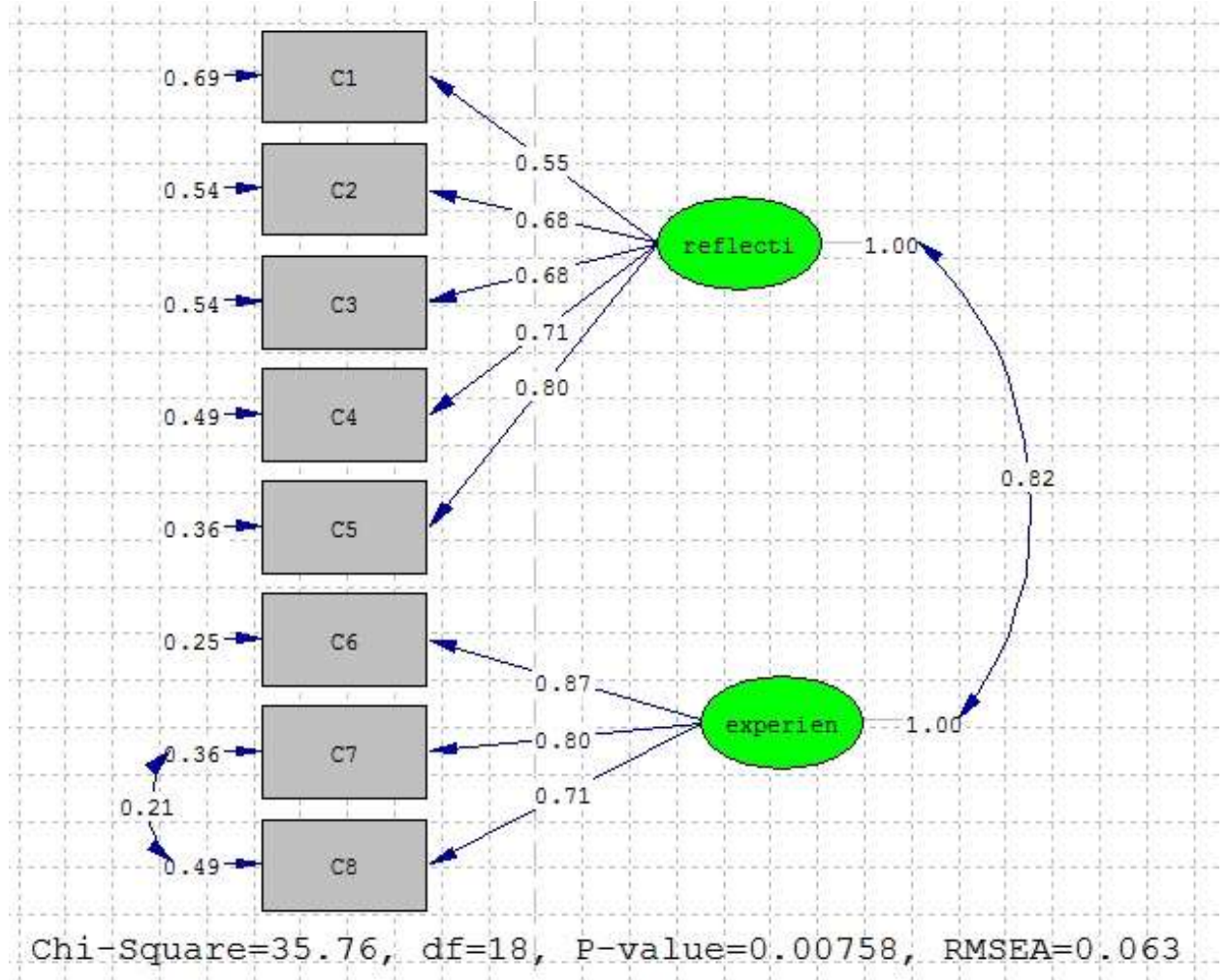

Fig. 1: Results of confirmatory factor analysis of Growth Motivation Index.

Reliability. Cronbach alpha internal consistency reliability coefficients of the were found as .81 for reflective subscale and .87 for experiential subscale. The corrected item-total correlations of Growth Motivation Index ranged from .56 to .84 .

TABLE I: Corrected item-total correlations of Growth Motivation Index

\begin{tabular}{ccccc}
\hline Item no & $\begin{array}{c}\text { Scale Mean if } \\
\text { Item Deleted }\end{array}$ & $\begin{array}{c}\text { Scale Variance if } \\
\text { Item Deleted }\end{array}$ & $\begin{array}{c}\text { Corrected Item- } \\
\text { Total Correlation }\end{array}$ & $\begin{array}{c}\text { Cronbach's Alpha } \\
\text { if Item Deleted }\end{array}$ \\
\hline 1 & 18,6008 & 20,459 &, 518 &, 807 \\
2 & 18,2258 & 20,977 &, 613 &, 776 \\
3 & 18,2742 & 20,337 &, 613 &, 775 \\
4 & 18,2097 & 20,183 &, 622 &, 772 \\
5 & 18,0605 & 20,381 &, 669 &, 760 \\
6 & 11,4476 & 6,103 &, 694 &, 875 \\
7 & 11,1815 & 5,518 &, 818 &, 760 \\
8 & 10,8065 & 6,254 &, 758 &, 818 \\
\hline \hline
\end{tabular}

\section{Discussion}

The purpose of this study was to translate Growth Motivation Index into Turkish and to examine its psychometric properties. Overall findings demonstrated that this scale had acceptable and fairly high validity and reliability scores and that it may be used as an efficient instrument in order to assess levels of growth motivation of individuals of. So it can be said that the Turkish version of Growth Motivation Index is a reliable and valid measure of the constructs it was intended to assess (Büyüköztürk, 2004; Marsh, Balla, \& McDonald, 1988; Tezbaşaran, 1996). Nevertheless, further studies that will use Growth Motivation Index are important for its measurement force. 


\section{References}

[1] Bauer, J. J., Park, S. W., Montoya, R. M., \& Wayment, H. A. (2015). Growth motivation toward two paths of eudaimonic self-development. Journal of Happiness Studies, 16, 185-210.

http://dx.doi.org/10.1007/s10902-014-9504-9

[2] Büyüköztürk, Ș. (2004). Veri analizi el kitabı. Ankara: Pegem A Yayıncılık.

[3] Marsh, H. W., Balla, J. R., \& McDonald, R. P. (1988). Goodness-of-fit indexes in confirmatory factor analysis: The effect of sample size. Psychological Bulletin, 103, 391-410.

http://dx.doi.org/10.1037/0033-2909.103.3.391

[4] Tezbaşaran. A. A. (1996). Likert tipi ölçek geliştirme kılavuzu. Ankara: Türk Psikologlar Derneği Yayınları. 